\title{
The truncated splice variant of peroxisome proliferator-activated receptor alpha, PPARa- tr, autonomously regulates proliferative and pro-inflammatory genes
}

Maria Thomas ${ }^{1 *}$, Christine Bayha ${ }^{1}$, Kathrin Klein ${ }^{1}$, Simon Müller ${ }^{1,4}$, Thomas S. Weiss ${ }^{2}$, Matthias Schwab $b^{1,3}$ and Ulrich M. Zanger ${ }^{1}$

\begin{abstract}
Background: The peroxisome proliferator-activated receptor alpha (PPARa) controls lipid/energy homeostasis and inflammatory responses. The truncated splice variant PPARa-tr was suggested to exert a dominant negative function despite being unable to bind consensus PPARa DNA response elements.

Methods: The distribution and variability factor of each PPARa variant were assessed in the well-characterized cohort of human liver samples $(N=150)$ on the mRNA and protein levels. Specific siRNA-mediated downregulation of each transcript as well as specific overexpression with subsequent qRT-PCR analysis of downstream genes was used for investigation of specific functional roles of PPARa-wt and PPARa-tr forms in primary human hepatocytes.

Results: Bioinformatic analyses of genome-wide liver expression profiling data suggested a possible role of PPARa-tr in downregulating proliferative and pro-inflammatory genes. Specific gene silencing of both forms in primary human hepatocytes showed that induction of metabolic PPARa-target genes by agonist WY14,643 was prevented by PPARa-wt knock-down but neither prevented nor augmented by PPARa-tr knock-down. WY14,643 treatment did not induce proliferative genes including MYC, CDK1, and PCNA, and knock-down of PPARa-wt had no effect, while PPARa-tr knock-down caused up to 3-fold induction of these genes. Similarly, induction of pro-inflammatory genes ILIB, PTGS2, and CCL2 by IL-6 was augmented by knock-down of PPARa-tr but not of PPARa-wt. In contrast to human proliferative genes, orthologous mouse genes were readily inducible by WY14,643 in PPARa-tr non-expressing AML12 mouse hepatocytes. Induction was augmented by overexpression of PPARa-wt and attenuated by overexpression of PPARa-tr. Pro-inflammatory genes including IL-1 $\beta$, CCL2 and TNFa were induced by WY14,643 in mouse and human cells and both PPARa forms attenuated induction. As potential mechanism of PPARa-tr inhibitory action we suggest crosstalk with WNT/ $\beta$-catenin pathway. Finally, treatment with WY14,643 in the presence of PPARa-tr resulted in the significant reduction of cell viability of AML12 and human ovarian cancer cell line, SKOV3.

Conclusions: Our data suggest that the truncated PPARa splice variant functions as an endogenous inhibitor of proliferative and pro-inflammatory genes in human cells and that its absence in mouse may explain species-specific differences in fibrate-induced hepatocarcinogenesis.
\end{abstract}

Keywords: Alternative splicing, Fibrates, Hepatocarcinogenesis, PPARA, Primary human hepatocytes, Inflammation, Proliferation, WNT/ß-catenin

\footnotetext{
* Correspondence: maria.thomas@ikp-stuttgart.de

'Dr. Margarete Fischer-Bosch Institute of Clinical Pharmacology, Auerbachstr.

112, 70736, Stuttgart, and University of Tuebingen, Tuebingen, Germany

Full list of author information is available at the end of the article
} 


\section{Background}

The nuclear receptors peroxisome proliferator-activated receptors (PPARs) are ligand-dependent transcription factors involved in diverse physiological roles such as lipid homeostasis, energy metabolism, inflammation, and cellular differentiation and proliferation [42]. The three related PPAR isotypes, PPAR $\alpha$ (NR1C1), PPAR $\beta / \delta$ (NR1C2), and PPAR $\gamma$ (NR1C3), share a high degree of homology but differ in tissue distribution and ligand specificity [13]. Because of their central role in regulating energy homeostasis and their often beneficial effects, PPARs are attractive pharmaceutical targets, in particular for the treatment of cardiovascular diseases [40] as well as obesity and other metabolic disorders [8].

A large body of literature described their essential role in cancer [26]. For instance, due to their antiproliferative, proapoptotic, and differentiation-promoting activity, $\mathrm{PPAR} \beta / \delta$ and PPAR $\gamma$ agonists have been extensively studied as potential anticancer agents [46]. The role of PPAR $\alpha$ in hepatic carcinogenesis appears to be speciesdependent. In some rodents, PPAR $\alpha$ has been implicated as a key mediator of non-genotoxic hepatocarcinogenesis. Thus, chronic treatment of rats and mice with PPAR $\alpha$ agonists (e.g., fibrate drugs) results in increased incidence of liver tumors through a PPAR $\alpha$-mediated mechanism [25, 29]. Importantly, however, these chemicals do not induce cell proliferation in human cells in vitro or cancer in humans, suggesting significant differences between human PPAR $\alpha$ and rodent Ppar $\alpha$ dependent regulatory pathways [1, 23]. Several factors were suggested to be responsible for the species-specific effects, including differences in the level of receptor expression [24], ligand affinity and other factors involved in PPAR $\alpha$ activation [12], as well as the profile of genes induced by mouse Ppar $\alpha$ versus human PPAR $\alpha$ following treatment with fibrate drugs [22, 44]. Interestingly, PPARA-humanized mice essentially lacked susceptibility to the hepatocarcinogenic effects of the peroxisomal proliferator model substance, WY14,643, and other fibrates, suggesting that structural differences between human and mouse PPAR $\alpha$ are at least in part responsible for the species difference in hepatocarcinogenesis $[22,36,44]$.

One striking discovery, which highlights the significance of sequence differences is the existence of an alternatively spliced transcript variant in humans but not in rodents $[9,24]$. The variant human PPARA-tr transcript lacks the entire exon 6 due to alternative splicing, leading to a premature stop codon and the generation of a truncated protein (PPAR $\alpha$-tr) with deficient ligand binding domain that is unable to bind to peroxisome proliferator-responsive DNA elements (PPRE) (Fig. 1). Nevertheless, based on luciferase reporter gene assays it has been suggested that PPAR $\alpha$-tr may exert dominant- negative functions [9]. In vivo evidence for this hypothesis is entirely lacking for humans. However in jerboas the PPAR $\alpha$-wt/PPAR $\alpha$-tr ratio was shown to depend on the hibernation cycle, thereby affecting the expression of metabolic target genes and lipid storage during feeding and hybernation phases [7]. Whether the endogenous human PPAR $\alpha$-tr has a specific physiological significance in regulating metabolic processes as well as its relevance for hepatocarcinogenesis remained unclear.

Here we used a combination of approaches to investigate the function of PPAR $\alpha$-tr in human and mouse hepatocytes in comparison to the canonical PPAR $\alpha$-wt form. We examined the expression of each PPARA form in a cohort of human liver samples on the protein and mRNA levels. Genome-wide correlation analysis with subsequent pathway enrichment analysis indicated a selective role for PPAR $\alpha$-tr as an antiproliferative and anti-inflammatory factor. Experimental manipulation of human and mouse hepatocytes by specific knock-down and overexpression constructs confirmed and further substantiated this hypothesis.

Our data suggest that the truncated PPAR $\alpha$ splice variant is differentially regulated and has autonomous functions in human hepatocytes and possibly other cells. Its absence in the mouse may explain species-specific differences in fibrate-induced hepatocarcinogenesis.

\section{Results}

PPARa-wt and PPARa-tr proteins are differentially regulated in human liver

We initially hypothesized that levels of endogenous PPAR $\alpha$-tr, given a general dominant negative function, should be negatively related to the expression of PPAR $\alpha$ target genes. We therefore assessed the expression of each transcript form in a well-characterized cohort of human liver samples $(N=150)$ [32]. Mean absolute transcript levels of PPARA-tr were approximately 5-fold lower compared to PPARA-wt (Fig. 2a), in line with previous reports of Gervois et al. [9] and Hanselmann et al. [14]. Both transcript forms varied considerably between the donors (wt, $\mathrm{CV}=44 \%$ and tr, $37 \%$ ), but their expression was well correlated (Spearman coefficient $r_{s}=0.52$; $P<0.0001)$. We used a polyclonal antibody targeting the common N-terminal part of PPAR $\alpha$ to simultaneously quantify the full-length $(52 \mathrm{kDa})$ and truncated $(30 \mathrm{kDa})$ protein forms (Fig. 2b). On average, PPAR $\alpha$-tr protein was $\sim 3$-fold lower expressed compared to PPAR $\alpha$-wt, indicating either more efficient translation or increased stability of the splice variant compared to the full-length form (Fig. 2b). Both PPAR $\alpha$-wt and PPAR $\alpha$-tr protein levels were not correlated to their respective transcript levels $\left(\mathrm{r}_{\mathrm{s}}=-0.05, P=0.5\right.$, for PPAR $\alpha$-wt and $\mathrm{r}_{\mathrm{s}}=0.03$, $P=0.7$, for PPAR $\alpha$-tr), indicating significant posttranscriptional regulation. In contrast to the correlated 


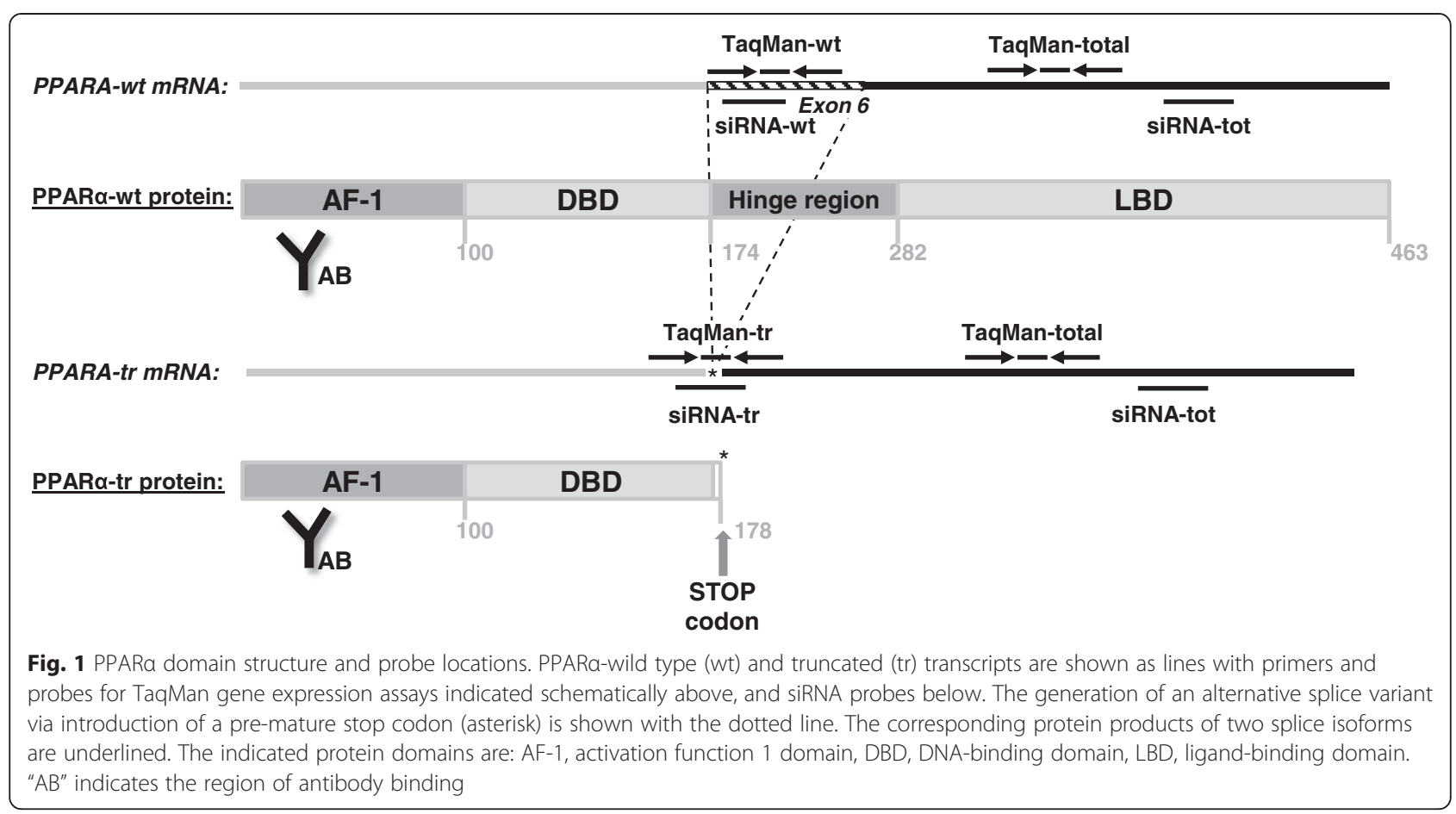

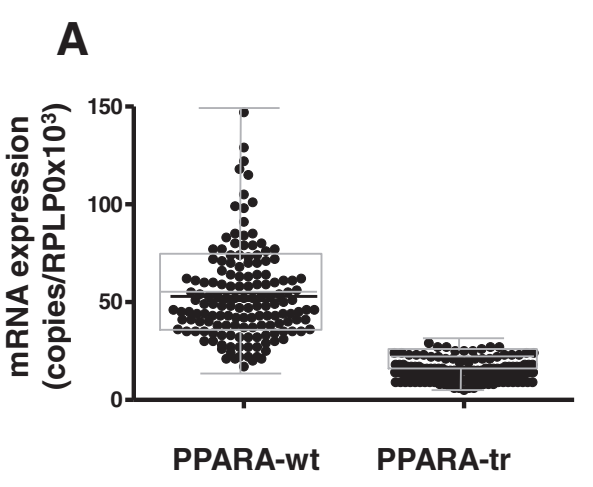

B

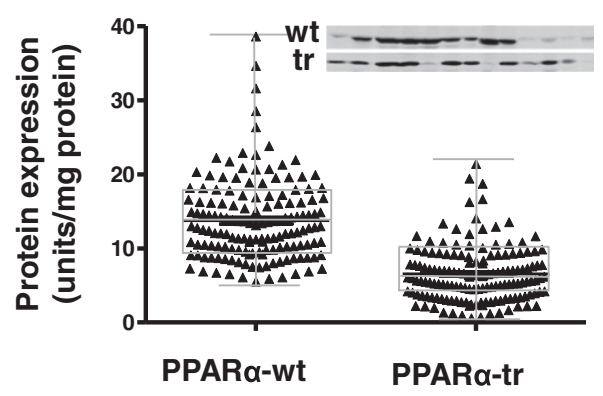

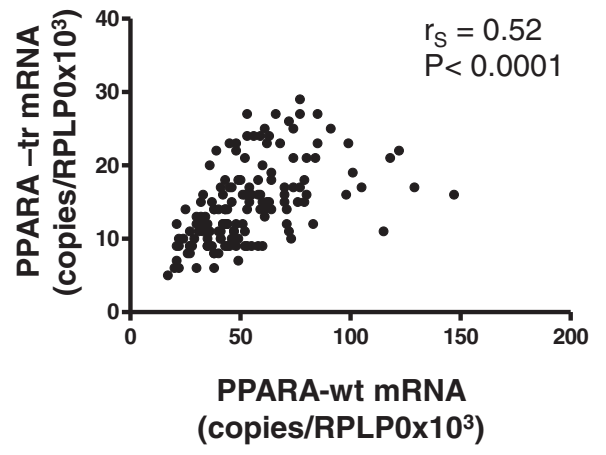

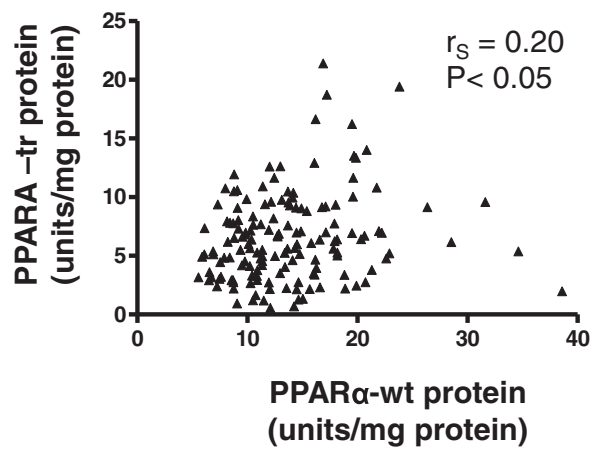

Fig. 2 Distribution and correlation of PPARa-wt and PPARa-tr variants in the human liver $(N=150)$. a Box-and-whisker plot reflecting the variability of mRNA copies for each PPARA transcript isoform (left-hand side). Expression correlation of both variants on the mRNA level (right-hand side). b Box-and-whisker plot reflecting the variability of the absolute amount of protein quantified by western blot for each PPARa isoform (left-hand side) with representative example blot as an insert. Correlation between both variants on the protein level (right-hand side) 
transcript levels, the protein levels of PPAR $\alpha$-wt and PPAR $\alpha$-tr were only marginally correlated to each other $\left(r_{\mathrm{s}}=0.20 ; P<0.05\right)$, suggesting that posttranscriptional regulation mechanisms differ between the two forms. This essential lack of correlation between the two forms resulted in $\approx 30$-fold variable PPAR $\alpha$-wt/ PPAR $\alpha$-tr ratio in the cohort compared to $\approx 7$-fold of PPAR $\alpha$-wt variability, thereby potentially extending the dynamic range of PPAR $\alpha$ function. Thus, a putative dominant negative function of PPAR $\alpha$-tr should become apparent by correlating PPAR $\alpha$ protein and gene expression levels.

PPARa-wt and PPARa-tr correlate with different gene sets To test this assumption, we performed Spearman correlation analyses between PPAR $\alpha$ protein forms and previously generated genome-wide mRNA expression profiles [32]. A total of 1586 genes were found to be positively correlated to PPAR $\alpha$-wt protein $\left(\mathrm{r}_{\mathrm{s}}>0.3, P<0.01\right.$, group A, Fig. 3a), compared to only 206 genes that were positively correlated to PPAR $\alpha$-wt/PPAR $\alpha$-tr protein ratio $\left(\mathrm{r}_{\mathrm{s}}>0.3, P<0.01\right.$, group B, Fig. 3a; see Additional file 1: Table S1 for Top 20 highest-ranked genes). The intersection between the groups A and B comprised only 92 genes (Fig. 3a). Pathway enrichment analyses using Reactome database revealed that genes positively correlated to PPAR $\alpha$-wt belonged to pathways of energy metabolism, specifically in terms of lipid, amino acids and carbohydrate biotransformation, including most of the well-known PPAR $\alpha$ target genes (Table 1, Group A). However, these terms were not enriched with either genes positively correlating with PPAR $\alpha$-wt/PPAR $\alpha$-tr ratio nor in the intersection between the two groups (Table 1, Groups B and Intersection).

Interestingly, within 239 genes negatively correlated to PPAR $\alpha$-tr protein (rs $<-0.3, p<0.01$; Fig. 3b, Group C), significantly enriched terms included immune system and WNT signalling as well as cell cycle but not classical metabolic pathways regulated by PPAR $\alpha$ (Table 1, Group C). Surprisingly, only five overlapping genes were represented in the intersection between the groups $\mathrm{A}$ and $\mathrm{C}$. These genes were so far not described as PPAR $\alpha$ target genes (Table 1, Intersection between the groups A and C).

Taken together, bioinformatic analysis of the gene groups correlating with either PPAR $\alpha$-wt/PPAR $\alpha$-tr protein ratio as well as of the intersection between PPAR $\alpha$ wt-positive and PPAR $\alpha$-tr-negative correlated genes did not support a significant and general dominant negative effect of PPAR $\alpha$-tr on the function of the canonical receptor. Interestingly, however, the data indicate that PPAR $\alpha$-tr may act rather independently by altering the expression sets of genes different from those regulated by the canonical receptor.

\section{PPARa-tr targets proliferative and pro-inflammatory genes}

To directly determine the effects of each PPAR $\alpha$ variant on expression of different classes of target genes in liver cells we designed specific siRNAs (Fig. 1). Selective targeting of each PPAR $\alpha$ variant was confirmed in primary human hepatocytes (PHH; Fig. 4a top). In particular, siRNA-tr transfection did not significantly decrease PPARA-wt, and siRNA-wt transfection did not decrease PPARA-tr. As shown by Western blot analysis, both PPAR $\alpha$ protein forms were effectively and specifically downregulated by these siRNAs (Fig. 4a bottom).

The assessment of downstream gene expression effects following application of the specific siRNAs was performed in combination with PPAR $\alpha$ activation by WY14,643 in PHH cultures of three independent hepatocyte donors (Fig. 4b). As expected, expression of four selected metabolic PPAR $\alpha$-target genes was significantly induced following treatment with WY14,643 (Fig. 4b,
A

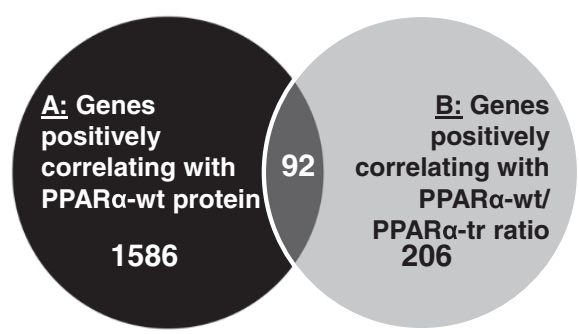

B

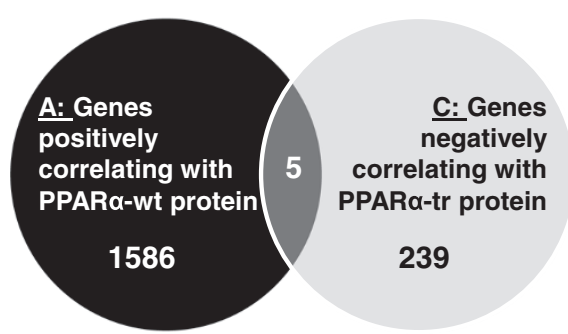

Fig. 3 Distribution of the genes using genome-wide correlation analysis in the cohort of human liver samples. a Venn diagram demonstrates the intersection (group I) between the positively correlated with PPARa-wt (black circle, group A) and with PPARa-wt/PPARa-tr ratio (dark-grey circle, group B) genes following genome-wide correlations between each PPARa protein form with the expression data assessed with Human-WG6v2 Illumina Expression microarrays. b Venn diagram shows the overlap between the positively correlated with PPARa-wt (black circle, group A) and with negatively correlated PPARa-tr (light-grey circle, group C) genes following genome-wide correlations between each PPARa protein form with the expression data assessed with Illumina microarrays. The 20 highest-ranked genes of each group are listed in the Additional file 1: Table S1 
Table 1 Pathway enrichment analysis using Reactome database of gene groups defined via correlation analysis of genome-wide gene expression data (for details see Fig. 3)

\begin{tabular}{|c|c|c|c|}
\hline Selected gene groups & Pathway term & $P$-value & Enrichment score \\
\hline \multirow[t]{5}{*}{ A: Positively correlating with PPARa-wt protein } & Metabolism of lipids and lipoproteins & 0.00002 & 10.4 \\
\hline & Biological oxidations & 0.005 & 2.89 \\
\hline & Integration of energy metabolism & 0.011 & 2.70 \\
\hline & Metabolism of amino acids & 0.015 & 2.48 \\
\hline & Metabolism of carbohydrates & 0.017 & 1.51 \\
\hline \multirow{5}{*}{$\begin{array}{l}\text { B: Positively correlating with PPARa-wt/PPARa-tr } \\
\text { protein ratio }\end{array}$} & Signaling by GPCR & 0.07 & 0.24 \\
\hline & Hormone biosynthesis & 0.09 & 0.17 \\
\hline & Synaptic Transmission & 0.19 & 0.15 \\
\hline & Apoptosis & 0.37 & 0.14 \\
\hline & Integration of energy metabolism & 0.40 & 0.09 \\
\hline \multirow[t]{5}{*}{ Intersection between the groups A and B } & Integration of energy metabolism & 0.0008 & 7.79 \\
\hline & Hemostasis & 0.002 & 6.36 \\
\hline & Signaling by BMP & 0.08 & 0.81 \\
\hline & HIV Infection & 0.028 & 0.74 \\
\hline & DNA Repair & 0.14 & 0.55 \\
\hline \multirow[t]{5}{*}{ C: Negatively correlating with PPARa-tr protein } & Signaling in Immune system & 0.029 & 1.06 \\
\hline & Cell Cycle, Mitotic & 0.047 & 0.88 \\
\hline & Signaling by Wnt & 0.042 & 0.63 \\
\hline & Apoptosis & 0.13 & 0.60 \\
\hline & IL3 signaling & 0.12 & 0.40 \\
\hline Intersection between the groups $\mathrm{A}$ and $\mathrm{C}$ & Full name & \multicolumn{2}{|c|}{ Functions } \\
\hline RBMS1 & $\begin{array}{l}\text { RNA Binding Motif, Single Stranded } \\
\text { Interacting Protein } 1\end{array}$ & \multicolumn{2}{|c|}{$\begin{array}{l}\text { Single-stranded DNA binding protein interacting } \\
\text { with upstream region of C-MYC gene. }\end{array}$} \\
\hline POFUT1 & Protein O-Fucosyltransferase 1 & \multicolumn{2}{|c|}{$\begin{array}{l}\text { Metabolic relevant enzyme, catalyzer of the fucose } \\
\text { attachement to serine/threonine residues. }\end{array}$} \\
\hline DEAF1 & DEAF1 Transcription Factor (also: suppressin) & \multicolumn{2}{|c|}{$\begin{array}{l}\text { Secreted factor, acts as an inhibitor of cell } \\
\text { proliferation by arresting cells in the G0 or } \\
\text { G1 phase. }\end{array}$} \\
\hline SLC6A9 & $\begin{array}{l}\text { Solute Carrier Family } 6 \text { (Neurotransmitter } \\
\text { Transporter, Glycine), Member } 9\end{array}$ & \multicolumn{2}{|c|}{$\begin{array}{l}\text { Terminates the action of glycine by its high affinity } \\
\text { sodium-dependent reuptake }\end{array}$} \\
\hline FLCN & Folliculin & \multicolumn{2}{|c|}{$\begin{array}{l}\text { Not clearly classified protein, involved in energy } \\
\text { and/or nutrient sensing via AMPK and mTOR } \\
\text { signaling pathways. }\end{array}$} \\
\hline
\end{tabular}

upper panel, white bars). SiRNA-mediated downregulation of PPARA-wt resulted in essentially complete block of induction of these genes (light grey bars), while knock-down of PPARA-tr did not have an effect (dark grey bars), suggesting that PPAR $\alpha$-tr has neither positive nor negative regulatory functions towards these classical PPAR $\alpha$ target genes. The levels of target gene expression following siRNA transfections and treated with the solvent control, DMSO, were used for the normalization and are represented by the dotted line. Additional file 2: Figure S2A (top) shows the mRNA expression changes relative to siRNA-ctr in the absence of the PPAR $\alpha$ ligand.
As shown in Fig. 4b (middle panel), the four selected proliferative genes were slightly but not significantly induced by WY14,643 treatment alone, suggesting that they are not directly regulated by PPAR $\alpha$. Consistently, specific knock-down of PPARA-wt did not have an effect. However, knock-down of PPARA-tr lead to significant, up to 3-fold upregulation of all but one (CDK4) of the four genes. In the Additional file 2: Figure S2A (middle) the mRNA expression changes relative to siRNA-ctr in the absence of WY14,643 are shown.

Four typical pro-inflammatory genes, IL1B, PTGS2, CCL2 and TNF were measured using a similar set-up with hepatocytes from the same donors as above but 

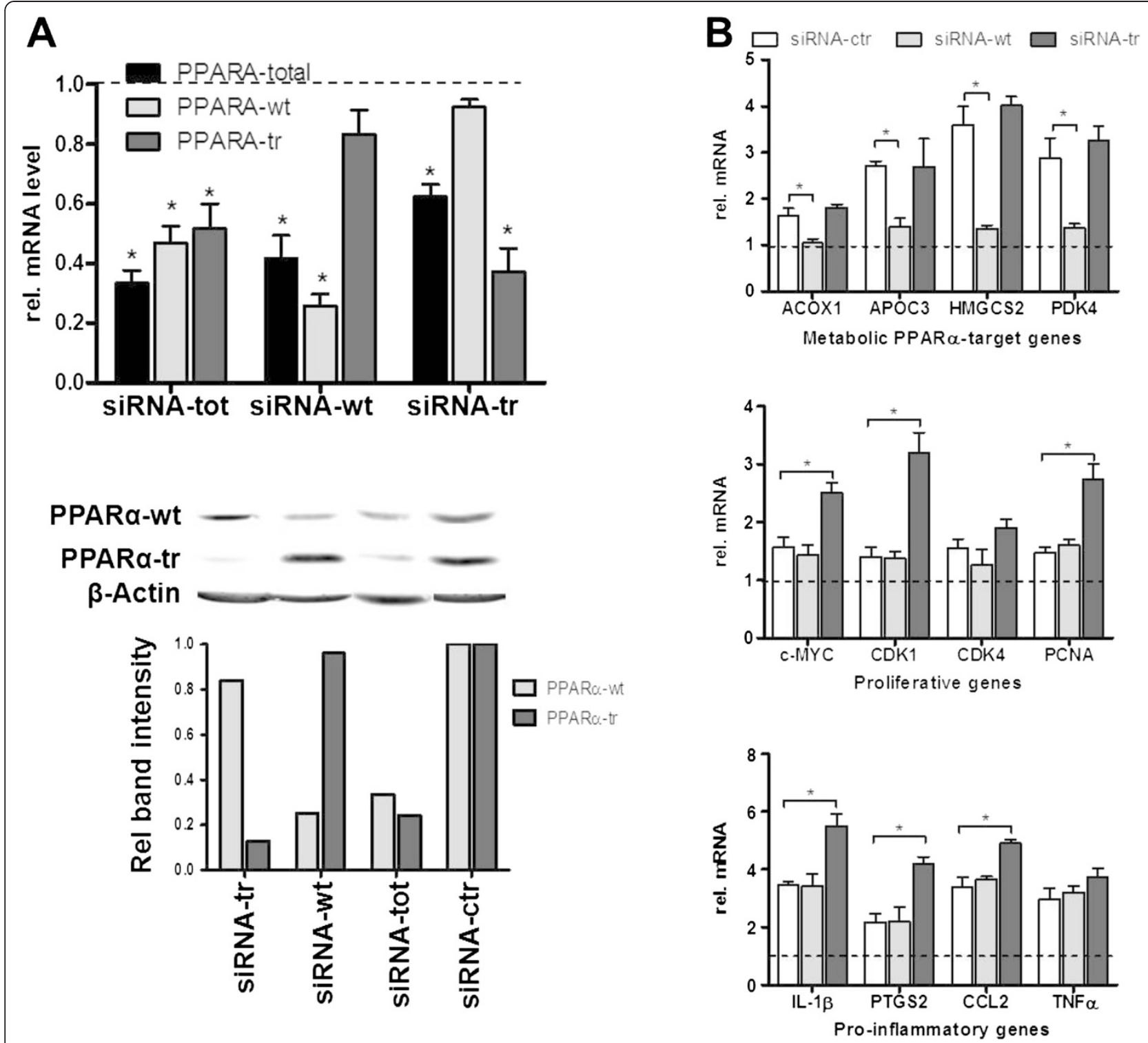

Fig. 4 Specific knock-down of PPARa transcript variants in primary human hepatocytes. a PHHs $(n=3)$ were transfected with siRNAs targeting PPARA-wt transcript only (siRNA-wt), PPARA-tr only (siRNA-tr), or both transcripts (siRNA-tot). Total and specific mRNA levels were determined by using specific TaqMan assays in comparison to non-targeting siRNA (siRNA-ctr; set to 1 and shown with the dotted line). Results represent means of three PHH donors with two individual replicates. Statistical significance was assessed by paired t-test in comparison to siRNA-ctr. At the bottom, PPARa protein was detected by Western blot analysis in total cell homogenates (50 $\mathrm{\mu g}$ per lane, representative western blot is shown) using a polyclonal antibody targeting the common N-terminal part of PPARa. The immunoreactive bands (upper panel) at $52 \mathrm{kDa}$ (PPARa-wt) and $30 \mathrm{kDa}$ (PPARa-tr) were densitometrically quantified and the intensities shown relative to the siRNA-ctr control. $\mathbf{b}$ Quantitative RT-PCR analysis of the selected canonical PPARa-target genes was performed in the cell lysates of A) $48 \mathrm{~h}$ after the transfection with the indicated siRNAs and treatment with WY14,643, in comparison to the cells transfected with siRNA-ctr and treated with the solvent control, DMSO (the dotted line) (Top panel Quantitative RT-PCR analysis of the selected proliferative genes was performed in the cell lysates of A) $48 \mathrm{~h}$ after the transfection with the indicated siRNAs and treatment with WY14,643 (middle panel). Quantitative RT-PCR analysis of the selected pro-inflammatory genes in the cell lysates of A) $48 \mathrm{~h}$ after the transfection with the indicated siRNAs and treatment with IL-6, in comparison to the cells transfected with siRNA-ctr and treated with the solvent control, PBS (the dotted line) (bottom panel). * indicates significance $p<0.05$

challenged with the pro-inflammatory cytokine IL-6 (Fig. 3, bottom panel). The expression levels of all four genes were significantly induced upon 48 hours of IL-6 treatment, demonstrating the triggering of an acute phase response. Except for TNF $\alpha$, expression was significantly upregulated following selective knock-down of PPARA-tr, while PPARA-wt had again no effect (Fig. 4, bottom panel). Additional file 2: Figure S2A (bottom) shows the mRNA expression changes relative to siRNA-ctr in the cells treated with the solvent control, PBS. 
Taken together, these experiments suggested that endogenous PPAR $\alpha$-tr attenuates the induction of several key proliferative genes by WY14,643 and of key proinflammatory genes by IL- 6 that are not classical PPAR $\alpha$ target genes in primary human hepatocytes.

\section{Proliferative genes are less sensitive towards PPARa regulation in human versus mouse}

Based on the previous experiments we hypothesized that the lack of PPAR $\alpha$-tr in mice could be a key factor for murine fibrate-induced hepatocarcinogenesis. To scrutinize this assumption we used mouse AML12 immortalized hepatocytes. We first verified that AML12 cells do not express PPAR $\alpha$-tr at the transcript and protein level (Additional file 3: Figure S1A and B).

Treatment of AML12 cells with WY14,643 lead to the induction of all four proliferative genes by $\sim 2.5$ to $\sim 5$-fold (Fig. 5a top). Transfection of PPAR $\alpha$-wt expression plasmid augmented induction of $M y c$ and Pcna approximately two-fold. In contrast, transfection of PPAR $\alpha$-tr attenuated induction of $M y c$ and $C d k 1$ significantly. Less profound, statistically not significant effects were observed for $C d k 4$ and Pcna. For comparison, exposure of human hepatoma cells HuH7 to WY14,643 induced only PCNA. While transfection of PPAR $\alpha$-wt had no augmenting effect on any proliferative gene, PPAR $\alpha$-tr overexpression significantly inhibited $M Y C$ expression and prevented induction of PCNA (Fig. $5 \mathrm{a}$ bottom).

In contrast to the proliferative genes, overexpression of both PPAR $\alpha$ forms had a significant inhibitory effect on the expression of most pro-inflammatory genes in hepatocytes of both species with PPAR $\alpha$-tr being considerably more effective than PPAR $\alpha$-wt (Fig. $5 b$ ).

Taken together these data suggested that these mouse proliferative genes are more susceptible towards PPAR $\alpha$ activation than the corresponding human genes but equally or even more effectively inhibitable by PPAR $\alpha$-tr, while both PPAR $\alpha$ variants show profound inhibitory effects on the expression of pro-inflammatory genes in both species.

Inhibitory functions of PPARa-tr can be mediated via WNT/ $\beta$-catenin pathway and/or via NF-kB pathway Considering that PPAR $\alpha$-tr variant does not bind to PPREs and does not act in a dominant negative fashion

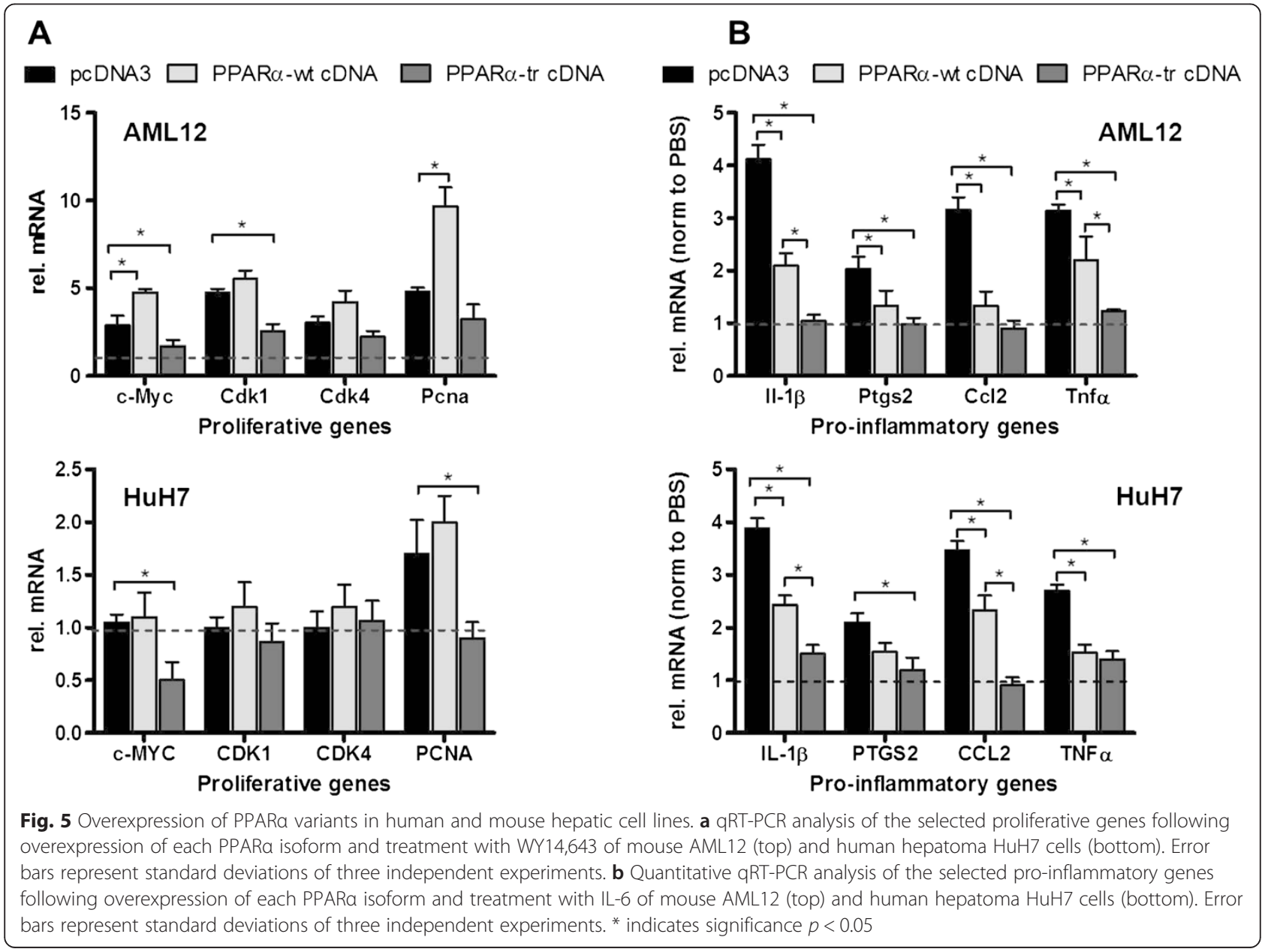


on the full-length receptor, we hypothesized that PPAR $\alpha$ tr exerts its inhibitory functions via crosstalk to other direct regulators of these genes. In particular, in silico analyses of canonical elements using TRANSFAC database revealed presence of TCF/LEF binding regions within the promoters of proliferative genes used in this study. Thus, a series of transfections with the luciferase reporter constructs carrying TCF/LEF binding elements in combination with either PPAR $\alpha$-wt or PPAR $\alpha$-tr cDNAs were performed in $\mathrm{HuH7}$ cells using co-stimulation of WNT/b-catenin pathway with the canonical natural WNT ligand, WNT3a. As shown in Fig. 6a, treatment with $20 \mathrm{ng} / \mathrm{ml} \mathrm{WNT3a} \mathrm{significantly} \mathrm{induced} \mathrm{the} \mathrm{luciferase}$ signal more than $\sim 5$ fold compared to the solvent control. Interestingly, combination of WNT3a treatment together with WY14,643 resulted in significant reduction of luciferase signal down to $\sim 3$ fold. Furthermore, co-transfection with PPAR $\alpha$-tr further decreased whereas transfection with PPAR $\alpha$-wt did not have any effect on the TCF/ LEF-mediated promoter activity. Finally, treatment with WNT3a alone in combination with PPAR $\alpha$-tr resulted in a similar downregulation of luciferase signal as in the presence of WY14,643.

Additionally we assessed activity of PPARa isoforms on the nuclear factor 'kappa-light-chain-enhancer' of activated B-cells, NF-kB - mediated regulation of the proinflammatory genes following treatment with IL-6. As shown in Fig. 6b, induction of an acute phase response resulted in the significant induction of NF-RE mediated luciferase signal more than $\sim 4$ fold compared to the solvent control. As expected, combination of IL-6 treatment together with PPAR $\alpha$-wt overexpression resulted in significant reduction of luciferase signal down to $\sim 3$ fold. However, co-transfection with PPAR $\alpha$-tr further significantly decreased NF-RE mediated promoter activity, indicating stronger inhibitory function of PPAR $\alpha-\operatorname{tr}$ in comparison to PPAR $\alpha$-wt. We therefore suggest that an intricate crosstalk of PPAR $\alpha$-tr with $\mathrm{WNT} / \beta$-catenin and NF-kB pathways might be a potential mechanism of PPAR $\alpha$-tr inhibitory activity on the expression of proliferative and inflammatory genes respectively, which definitely warrants further detailed investigation.

\section{PPARa-tr inhibits proliferation of mouse hepatocytes and} human cancer cells

To further explore whether inhibitory effects of PPAR $\alpha$ tr on the expression of proliferative genes affects cell viability, AML12 cells were treated with WY14,643 in the presence or absence of PPAR $\alpha$-tr (Fig. 7a, upper panel). In line with previous results on the WY14,643mediated inducibility of proliferative genes in mouse, increased proliferation of mouse hepatocytes towards treatment with WY14,643 was observed (Fig. 7a, upper panel, line with circles). Remarkably, overexpression of PPAR $\alpha$-tr in these cells not only reversed the effect of the PPAR $\alpha$ activator, but further decreased viability on day 12 substantially below control levels (vector-transfected cells treated with WY14,643). In contrast, treatment of HuH7 cells with WY14,643 alone lead to decreased cell viability on day 12 (Fig. 7a, bottom panel, line with circles). However, transfection of PPAR $\alpha$-tr did not lower $\mathrm{HuH} 7$ cell viability (Fig. 7a, bottom panel, line with squares). To test whether viability of other cancer cells is susceptible towards fibrates and overexpression of PPAR $\alpha$-tr, we performed the same experiments in the
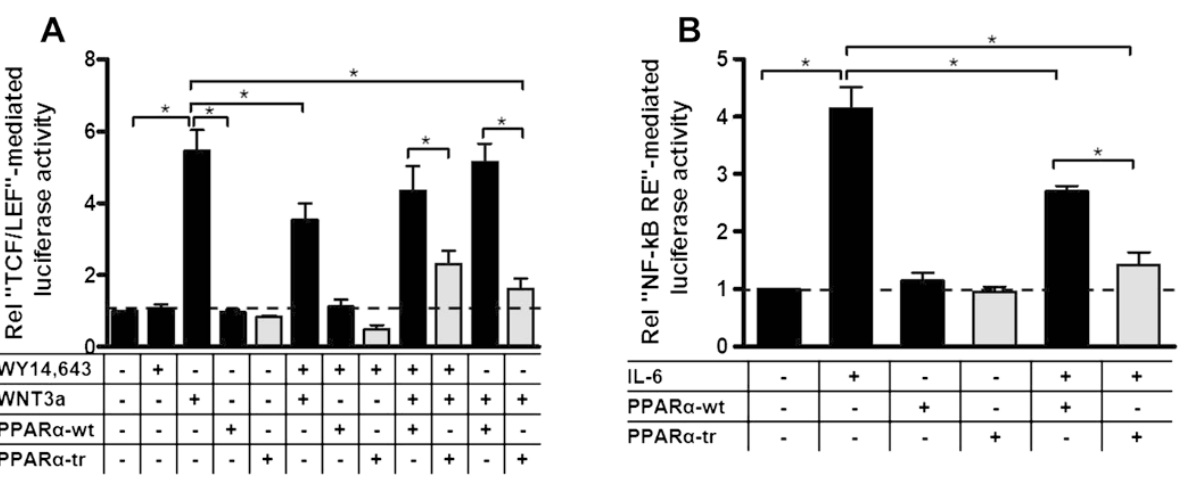

Fig. 6 Differential activity of PPARa-wt and PPARa-tr on the WNT/ $\beta$-catenin and NF-kB promoter binding elements. a Quantitative luciferase reporter gene assays with the constructs containing 4XTCF/LEF response elements were performed in human HuH7 cells $48 \mathrm{~h}$ after indicated treatments and in total $72 \mathrm{~h}$ after the transfection with the indicated constructs. The bars represent the fold induction of luciferase activity normalized to the control state without any treatment (indicated with the dotted line). Error bars indicate standard deviation between three independent experiments. * indicates siginificance $p<0.05$. b. Quantitative luciferase reporter gene assays with the constructs containing $3 \times \mathrm{NF}$-kB response elements were performed in human HuH7 cells $48 \mathrm{~h}$ after indicated treatments and in total $72 \mathrm{~h}$ after the transfection with the indicated constructs. The bars represent the fold induction of luciferase activity normalized to the control state without any treatment (indicated with the dotted line). Error bars indicate standard deviation between three independent experiments. * indicates siginificance $p<0.05$ 

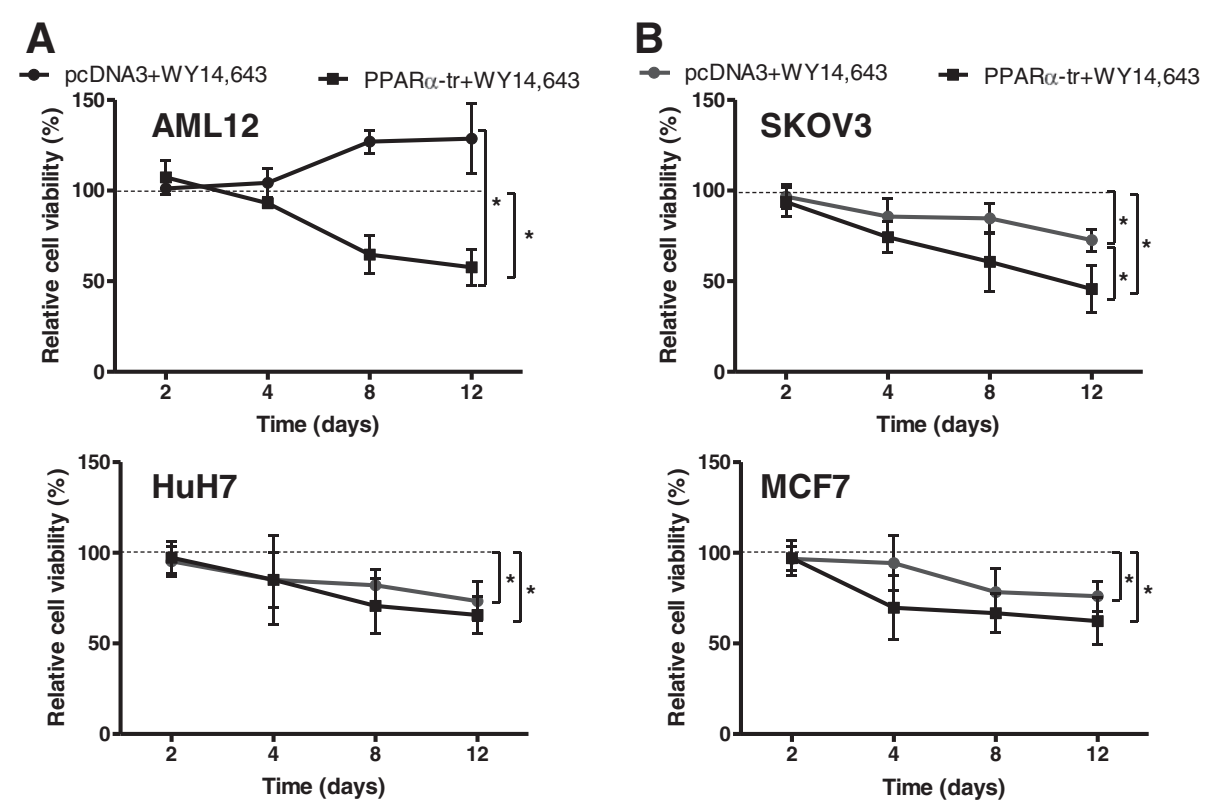

Fig. 7 Cell viability analysis following PPARa-tr overexpression in mouse and human cancer cells. AML12 (a, top), HuH7 (a, bottom), SKOV3 (b, top) and MCF7 (b, bottom) cells were transfected with indicated constructs treated with $100 \mu \mathrm{M}$ WY14,643 and cell viability was measured using CellTiterGlo assay at the indicated days. The viability curves are shown relative to the pcDNA3-transfected cells treated with solvent control, DMSO, set as $100 \%$ (dashed line). Error bars indicate standard deviation between three independent experiments measured in triplicates.

* indicates significance $p<0.05$

human ovarian carcinoma cell line, SKOV3 (Fig. 7b, upper panel) and the human breast cancer cell line, MCF7 (Fig. 7b, bottom panel). In both cases, treatment with WY14,643 significantly reduced cell viability until day 12. Transfection of SKOV3 cells with the truncated variant of PPARa led to the further significant reduction of cell viability while the effect on MCF7 cells was also consistent over time, yet did not reach statistical significance (Fig. $7 \mathrm{~b}$, bottom panel).Of note, the cell viability curves generated for SKOV3 cells overexpressing either PPAR $\alpha$-wt or PPAR $\alpha$-tr cDNA in the presence of two additional PPAR $\alpha$ ligands, clofibrate and GW7647, confirmed that the observed effects are not due to a ligand dependent effect on different splice variants (Additional file 4: Figure S3).

\section{Discussion}

Despite its initial identification and characterization in the late 1990s, the function of the C-terminally truncated PPAR $\alpha$ splice variant in human cells has remained speculative. Although in vitro data suggested a possible dominant negative function, no direct or supporting in vivo data had been provided so far. On the other hand, several recent papers suggested an involvement of the variant in the lack of fibrate-mediated hepatocarcinogenesis in humans, but data supporting this hypothesis are also lacking $[4,12,21]$. Here we used human liver samples to characterize expression and interindividual variability of the two PPAR $\alpha$ splice variants in relation to genome-wide target gene expression, which indicated potentially differential roles. Assessment of the distribution of each PPAR $\alpha$ form in the cohort of liver tissues revealed high correlation of mRNA levels of both variants to each other. This is in accordance with Hanselman et al. [14], who also reported high correlation of mRNA levels between PPARA-wt and PPARA-tr in 18 human livers $\left(r_{s}=0.75\right)$. However, our assessment of the protein isoforms in a cohort of human liver samples revealed the interesting novel observation, that the protein levels of the canonical and variant splice receptor forms are much less correlated than the transcripts, indicating significant posttranscriptional regulation. It should be interesting to investigate whether microRNAs contribute to this divergent expression.

Newly designed isoform-specific tools used to study their function in human and mouse cell models demonstrated that silencing of PPAR $\alpha$-tr in human hepatocytes had no effect on several classical PPAR $\alpha$ target genes, thus arguing against a general function of the splice variant as dominant negative regulator. Instead, the variant isoform appears to have an autonomous function as negative regulator of proliferative and pro-inflammatory genes. As shown in Fig. 4b (upper panel), we did not observe any effect of specific siRNA-mediated inhibition of the endogenous PPAR $\alpha-\operatorname{tr}$ on the expression of ACOX1 or other canonical PPAR $\alpha$ target genes in 
primary human hepatocytes of three independent donors. Although we cannot absolutely exclude any dominantnegative activity of PPAR $\alpha$-tr on the full-length PPAR $\alpha$ wt, a general function as such appears to be unlikely. This discrepancy between the earlier in vitro study [9] and our study could be due to several reasons. It is possible that the difference is merely of quantitative nature, i.e. the true effect may have been overestimated by the in vitro constructs used in the earlier study, and they may be too small to be detectable in our model system of primary human hepatocytes. Another explanation could be that the negative effects observed depend on nuclear translocation of PPAR $\alpha$ tr, as suggested previously. While in the former study nuclear translocation had been achieved by a nuclear localization signal fused to the $\mathrm{N}$-terminus, translocation in vivo may depend on physiological conditions.

Our data strongly suggest that PPAR $\alpha$-tr acts independently of PPAR $\alpha$-wt in negatively regulating proliferative and pro-inflammatory gene sets. This conclusion is based on several complementary observations. First, bioinformatic analyses revealed that there were virtually no genes showing positive correlation to the canonical receptor and simultaneous negative correlation to the splice variant, as would be expected if there was a dominant negative influence. Second, our specifically designed gene silencing probes clearly showed strong effects on several proliferative and proinflammatory genes, whereas the knock-down of the canonical receptor had no effect. Third, essentially complementary results were obtained by specific overexpression of the two variants in various cells.

Evidence for an involvement of PPAR $\alpha$-tr in transcriptional regulation of specific genes distinct from PPAR $\alpha$-wt pathways has also been provided by others. Beaumont et al. described a mechanism of apoptosis induction following overexpression of PPAR $\alpha$-tr in human cardiomyocytes via downregulation of the anti-apoptotic protein, Bcl-2 [2]. Goikoetxea et al. found lower expression of PPAR $\alpha$-wt and higher expression of PPAR $\alpha-\operatorname{tr}(P<0.001)$ in endomyocardial septal biopsies from patients with heart failure [11]. The apoptose index was directly correlated to PPAR $\alpha$-tr suggesting that PPAR $\alpha$-tr has a role in the pathophysiology of the left ventricle. Interestingly, divergent gene regulation between a canonical and a splice variant has also been found for the beta isoform splice variant of the human GR [15]. This truncated form may alter gene transcription independent from the canonical receptor and increased GR-beta levels were correlated with glucocorticoid resistance and the occurrence of several immune-related diseases. It is important to mention that the significant effects of PPAR $\alpha$-tr were observed only in the presence of PPAR $\alpha$ ligand, WY14,643. Since PPAR $\alpha$-tr lacks the ligand-binding domain, both ligand-mediated activation of the full-length protein or PPAR $\alpha$-independent effects of WY14,643 could be involved in the activation of PPAR $\alpha$-tr. Indeed, it is known that PPAR $\alpha$ regulates its own expression [27] and thus can be associated with the direct generation of its own alternative splice variant. Furthermore, regulation via post-translational modifications could be an additional mechanism of PPAR $\alpha$-tr activation [6, 41]. It is important to mention that our experiments using additional PPAR $\alpha$ agonists, such as clofibrate or GW7647, further confirmed ligand-independent nature of the differential functions of PPAR $\alpha$ isoforms (Additional file 4: Figure S3).

The interplay between PPAR $\alpha$ and pro-inflammatory genes was studied previously [10, 20,35]. Surprisingly, however, we could see no effect of siRNA-mediated downregulation of an endogenous PPAR $\alpha$-wt on the expression of pro-inflammatory genes in $\mathrm{PHH}$ (Fig. 4b, bottom panel). We speculate that anti-inflammatory PPAR $\alpha$-mediated effects can be attributed to the function of PPAR $\alpha-\operatorname{tr}$ via interference with NF-kB pathway. Indeed, luciferase reporter gene assays using luciferase constructs containing NF-kB response elements (NF-kB RE) further supported this hypothesis (Fig. 6b). Although overexpression of PPAR $\alpha$-wt resulted in the reduced NF-kB RE-mediated luciferase expression, transfection with PPAR $\alpha$-tr led to even stronger inhibition of the luciferase signal. Recently, we described a novel regulatory crosstalk between PPAR $\alpha$ and $\mathrm{WNT} / \beta$-catenin pathways [37]. Our study strongly indicates the intensive crosstalk between PPAR $\alpha$ and $\beta$-catenin in the regulation of the downstream target genes of both transcription factors. Based on the luciferase reporter gene assays, we suggest that truncated PPAR $\alpha$ variant might be involved in the negative regulation of proliferative gene expression presumably via interaction with $\beta$-catenin. Interestingly, $\mathrm{WNT} / \beta$-catenin signalling pathway was also significantly enriched with genes negatively correlating with PPAR $\alpha-$ tr protein expression in our bioinformatic analysis of liver samples (Fig. 3, right box), implying involvement of PPAR $\alpha$-tr in the regulation of other factors within this cascade. Undoubtedly, additional studies are required for the further understanding of the interplay between these two pathways.

Determining the mode of action of PPAR $\alpha$ ligands in causing liver cancer in rodent models and the mechanism of the species differences are of great importance since fibrate drugs are widely used in the clinics. Furthermore, new generation drugs, with PPAR $\alpha$ agonist activity $\left(\mathrm{EC}_{50}\right)$ of more than 100 -fold greater than the fibrates, are under development by the pharmaceutical industry [43]. It is meanwhile clear that fibrates itself do not cause genetic damage but rather metabolic alterations or interference with the cell cycle, resulting from sustained receptor activation contribute to oxidative 
stress induced DNA damage promoting hepatocarcinogenicity. Furthermore, several studies suggested induced expression of c-Myc protein to be the mechanism contributing to PPAR $\alpha$ ligand-induced hepatocellular proliferation [30]. Our data showing the prevention of c-Myc induction by PPAR $\alpha$-tr following PPAR $\alpha$ activation supports this hypothesis (Fig. 4b and Fig. 5a). Additionally, we observed higher susceptibility of several key proliferative genes to the WY14,643-mediated PPAR $\alpha$ induction in mouse compared to human cells (Fig. 5a). Thus, we suggest that both higher induction of proliferative genes and lack of the inherent inhibitory control-mechanism by the truncated splice form contribute to fibrateinduced carcinogenesis in mice.

Several recent studies have revealed that PPAR $\alpha$ ligands suppress the growth of human cancer lines, including colon, breast, endometrial and skin, in vitro $[19,31,33]$. Clofibric acid inhibits the growth of human ovarian cancer in mice [45]. Furthermore, it was shown that PPAR $\alpha$ agonist, WY14,643, suppresses tumorigenesis in a PPAR $\alpha$-dependent manner [28]. The antitumor properties of PPAR $\alpha$ ligands appear to be mediated primarily by their direct and indirect anti-angiogenic effects and their anti-inflammatory activity but also by direct antitumor effects, without so far clearly defined mechanisms. Based on our studies, we suggest that the truncated PPAR $\alpha$ splice variant provides protective mechanism in acting as an endogenous inhibitor of proliferative and proinflammatory genes in human cells and its absence in mouse may explain species-specific differences in fibrateinduced hepatocarcinogenesis. We hope our findings will help in further development and improvement of anticancer therapy using already approved PPAR $\alpha$ agonists.

\section{Conclusions}

Based on our studies, we suggest that the truncated PPAR $\alpha$ splice variant exerts antitumor effects via synergistic downregulation of proliferative and antiinflammatory genes in human cells. Its absence in mouse may explain species-specific differences in fibrate-induced hepatocarcinogenesis.

\section{Methods}

\section{Cell lines and treatments}

Primary human hepatocytes (PHH) were isolated from partial liver resections by collagenase digestion as described previously [5]. Cells were cultured in William's E Medium (Invitrogen Life Technologies, Darmstadt, Germany), supplemented with $10 \%$ fetal bovine serum (FBS) (PAA Laboratories GmbH, Pasching, Austria), $1 \%$ penicillin/streptomycin (GIBCO, Carlsbad, USA), $1 \mathrm{mM}$ glutamine (GIBCO, Carlsbad, USA), 16 I.U. human insulin (Sanofi, Frankfurt, Germany), 0.1 \% dimethyl sulfoxide (DMSO) (Sigma-Aldrich, Steinheim, Germany), and
$50 \mathrm{mM}$ dexamethasone (Sigma-Aldrich, Steinheim, Germany). Medium was changed daily.

Mouse $A M L 12$ and human hepatoma $\mathrm{HuH7}$ cells were cultured at $37{ }^{\circ} \mathrm{C}$ with $5 \% \mathrm{CO}_{2}$ concentration and passaged every 3-4 days by the Trypsin/EDTA method. HuH7, SKOV3 and MCF7 cells were cultured in Dulbecco's Modified Eagle Medium (DMEM) with $10 \%$ fetal calf serum (FCS) gold (PAA Laboratories GmbH, Pasching, Austria), $1 \%$ penicillin/streptomycin, and $1 \%$ pyruvate. AML12 cells were cultivated in DMEM-F12 medium with $10 \%$ FCS, $1 \%$ penicillin/streptomycin, and $1 \%$ glutamine.

For the induction experiments cells were treated for the indicated times either with $100 \mu \mathrm{M}$ of WY14,643, $100 \mu \mathrm{M}$ of clofibrate or $10 \mu \mathrm{M}$ of GW7647 (all purchased at Sigma-Aldrich, Steinheim, Germany) dissolved in DMSO, or with $10 \mathrm{ng} / \mu \mathrm{l}$ of human recombinant interleukin-6 (PromoCell GmbH, Heidelberg, Germany) in phosphate buffered saline (PBS) (GIBCO, Carlsbad, USA), supplemented with $0.1 \%$ bovine serum albumin (BSA) (Sigma-Aldrich, Steinheim, Germany), or vehicle only (DMSO or PBS $+0.1 \%$ BSA). During the knockdown experiments, the chemicals were added 4 hours after the siRNA transfections. In the overexpression experiments, substances were added $24 \mathrm{~h}$ after the transfection of the vectors. The time on the diagrams indicates time upon start of the treatments.

\section{Human liver cohort}

Liver tissues and corresponding blood samples were previously collected from 150 patients of Caucasian ethnicity (71 males and 79 females; average age of the subjects $58 \pm 14 \mathrm{y})$. Patients who suffered from hepatitis, cirrhosis, or alcohol abuse were excluded. All tissue samples had been examined by a pathologist and only histologically non-tumorous tissue was used [17]. The study was approved by the ethics committees of the medical faculties of the Charité, Humboldt University, and of the University of Tuebingen and conducted in accordance with the Declaration of Helsinki. Written informed consent was obtained from each patient.

\section{Quantitative real-time RT-PCR analysis}

Total RNA was isolated using the RNeasy Mini Kit, including on-column genomic DNA digestion with RNase free DNase Set (Qiagen, Hilden, Germany) as previously described [39]. RNA integrity and quantity were analyzed with the Agilent 2100 Bioanalyzer using the RNA 6000 Nano Kit (Agilent Technologies, Waldbronn, Germany). Synthesis of cDNA was performed with 500 ng RNA using Taqman Reverse Transcription Reagents (Applera GmbH, Darmstadt, Germany). Quantification of PPAR $\alpha$ target gene expression was performed either using ABI Prism 7900HT Taqman (Applied Biosystems) or Fluidigm's BioMark HD high-througphut 
quantitative chip platform (Fluidigm Corporation, San Francisco, USA), following the manufacturer's instruction [34]. The following validated gene expression TaqMan $^{\circ}$ assays from Applied Biosystems were used: GAPDH (Hs00266705_g1), ACOX1 (Hs01074241_m1), APOC3 (Hs00163644_m1), HMGCS2 (Hs00985427_m1), PDK4 (Hs01037712_m1), MYC (Hs00153408_m1), CDK1 (Hs00938777_m1), CDK4 (Hs00262861_m1), PCNA (Hs00696862_m1), IL-1 $\beta$ (Hs01555410_m1), PTGS2 (Hs00153133_m1), CCL2 (Hs00234140_m1), TNF (Hs01113624_g1)Gapdh (Mm99999915_g1), c-Myc (Mm00487804_m1), Cdk1 (Mm00772472_m1), Cdk4 (Mm00726334_s1), Pcna (Mm00448100_g1), Il-1 $\beta$ (Mm00434228_m1), Ptgs2 (Mm00478374_m1), Ccl2 (Mm00441242_m1), Tnfo (Mm00443258_m1). The mRNA expression levels were normalized to glyceraldehyde-3-phsophate dehydrogenase (GAPDH/Gapdh) mRNA levels.

For the detection of PPAR $\alpha$ isoform expression in the liver samples $(N=150)$, specific primers and the probe for the detection of only wild-type transcript, positioned within the $6^{\text {th }}$ exon, and for truncated variant, positioned on the $5^{\text {th }}$ and $7^{\text {th }}$ exon and the probe exactly on the junction site, were designed (for schematic representation see Fig. 1). Expression plasmids for each isoform were in parallel run in dilutions for the calibration of absolute amount of the transcripts in the liver samples as it was previously described [16] and normalized to RPLP0 (Hs99999902_m1) expression.

\section{Expression constructs for PPARa isoforms}

Human PPAR $\alpha$ expression plasmid pcDNA3-hPPAR $\alpha$ was a kind gift of T. Tanaka (24). Expression vector of PPAR $\alpha$ splice variant missing exon 6 was constructed from pcDNA3-hPPAR $\alpha$ by amplification of fragment F1 using primers T7_fw (TAATACGACTCACTATAGGG) and ex5/7_rev (GTCACACAACGCCTTTTGTCATAC ATGATATGG) and fragment F2 using primers ex5/7_fw (TATGACAAAAGGCGTTGTGTGACATCCCG) and pcDNA_rev (TAGAAGGCACAGTCGACG). Using both fragments, a PCR fusion (sequence overlap is underlined) was performed using T7_fw and pcDNA_rev primers to form a 1429bp product, which was cloned into pCR4TOPO vector (Life technologies, Carlsbad, Germany). The correct fusion and complete cDNA sequence was confirmed by sequencing of both strands. Exchange of a $1.32 \mathrm{kB} \mathrm{BamHI} / A p \mathrm{aI}$ fragment in the full length parent derivative resulted in pcDNA3-hPPAR $\alpha$-tr.

\section{Western blot analysis}

For the simultaneous measurements of PPAR $\alpha$ isoforms in the cohort of liver samples, $50 \mu \mathrm{g}$ of tissue homogenate was electrophoretically separated on a $10 \%$ SDSPolyacrylamide gel and subsequently transferred to a nitrocellulose membrane using a Trans-blot semi-dry Fastblot 44 transfer chamber (Biometra, Goettingen, Germany). After blocking with $5 \%$ skim milk in TBST membranes were incubated with the primary antibodies in $1 \%$ skim milk solution in TBST. For the detection of the protein levels of each isoform we used a polyclonal antibody detecting both isoforms (rabbit anti-human PPARa, CAYMAN No. 101710, dilution 1:500). The following additional antibodies and dilutions were used: mouse anti- $\beta$-Actin (Sigma-Aldrich, A5441, 1:500) was used to detect $\beta$-Actin for normalisation; goat-antirabbit-IRD800 (Li-COR, 926-32214, 1:10.000) and goatanti-mouse-IRD650 (Li-COR, 926-68074, 1:10.000) were fluorescently labeled secondary antibodies. Membranes were washed 4 times with TBST for $15 \mathrm{~min}$ before they were incubated with the secondary antibody for $30 \mathrm{~min}$ at room temperature. Detection was performed with a Li-COR Odyssey CLx fluorescence reader (Bad Homburg, Germany). Serial dilutions of a liver homogenate with good expression of both PPAR $\alpha$ isoforms were run on each gel and used for inter- and intramembrane calibration.

\section{Transfections with siRNAs and cDNAs}

For the RNAi experiments, PHHs were transfected with $20 \mathrm{nM}$ siRNAs using 10 pmol of Lipofectamine RNAiMAX Transfection Reagent (Life Technologies, Carlsbad, Germany) in 12-well plates with serum free medium. The indicated siRNAs specifically targeting PPAR $\alpha$ variants were custom designed and a nontargeting siRNA as a negative control (Lo GC Duplex \#2) were obtained from Life Technologies (Carlsbad, Germany). To the cells containing $100 \mu \mathrm{l}$ culture medium, $100 \mu \mathrm{l}$ of the transfection cocktail was added to each well after 4-6 hours of incubation time following arrival. For overexpression, $200 \mathrm{ng}$ of cDNA vectors were mixed with $2 \mu \mathrm{l}$ of Lipofectamine 3000 Reagent (Life Technologies, Carlsbad, Germany) and upon 20 minutes of complex formation, the liposomes were given to the cells plated in 24well plates for the analysis of gene expression.

\section{Luciferase reporter gene assays}

The reporter gene assays were performed as previously described [38]. The pGL3 containing TCF4/LEF response element upstream of luciferase genes was a gift of Prof. Wehkamp [18]. pGL4.32 Vector containing five copies of an NF- $\mathrm{KB}$ response element (NF- $\mathrm{KB}-\mathrm{RE})$ that drives transcription of the luciferase reporter gene was purchased by Promega (Mannheim, Germany).

\section{CellTiter Glo luminescent cell viability assay}

The CellTiter-Glo luminescent cell viability assay (Promega, Mannheim, Germany) is based on the quantitation of ATP, reflecting the presence of metabolically active or viable 
cells. Cells were seeded in 96-well clear bottom opaque plates (6005199, Perkin Elmer, Rodgau Germany) at $1 \times 10^{3}$ cells/well density. The cells were transfected with pcDNA3 control vector or pcDNA3, containing cDNA of PPAR $\alpha$-tr and cultured for 12 days. At day 1 after seeding, cells were treated with $20 \mathrm{ng} / \mathrm{ml}$ WNT3a (Sigma, Taufkirchen, Germany; dissolved in $0.1 \%$ bovine serum albumin) and WNT3a treatment was repeated without additional medium change at days 5 and 6 . Medium containing WY14,643 was changed daily to keep PPAR $\alpha$ activated. On the indicated days, an equal volume of reconstituted CellTiter-Glo reagent was added to $50 \mu \mathrm{l}$ of cultured cells in three wells per time point and treatment. The contents were mixed for 2 minutes to induce cell lysis. The luminescent signal was measured using multimode reader Enspire (Perkin Elmer, Rodgau, Germany).

\section{Statistical analyses}

Statistical analyses were performed using software R2.11.0 [3]. For the genome-wide correlation analyses, whole genome gene expression profiles of the 150 particularly well-characterized samples were generated by using Human-WG-6v2 Expression BeadChips (Illumina, Eindhoven, Netherlands) and are publically available [32]. After combining synonymous probe sets and removal of probes that did not correspond to a mapped gene, 24,754 genes were selected for further analyses. Spearman correlation was calculated between mRNA transcripts and the protein levels of PPAR $\alpha$-wt, PPAR $\alpha$-tr, and PPAR $\alpha$-wt $/$ PPAR $\alpha$-tr ratio in 150 liver samples. Transcripts correlated with each PPAR $\alpha$ protein form at $r_{s} \geq 0.3$ and $p<0.01$ were used for the enrichment analysis using the pathway database, Reactome (www.reactome.org).

For demonstration of gene expression changes, the mean fold changes as obtained from the $\Delta \Delta C T$-method and their standard deviations were calculated. To determine the significance of gene expression changes, grouped t-test with Bonferroni post-hoc-test for multiple comparisons was applied using GraphPad Prism 5.0.4 software (GraphPad Software, Inc., La Jolla, USA).

\section{Additional files}

Additional file 1: Table S1. The 20 highest ranked genes in the defined groups according to Spearman correlation analysis of genome-wide gene expression data (see also Fig. 3).

Additional file 2: Figure S2. Expression levels of the target genes following transfections with siRNAs in the absence of WY14,643 (A, B) or IL-6 (C). A. PHHs $(n=3)$ were transfected with siRNAs targeting PPARA-wt transcript only (siRNA-wt), PPARA-tr only (siRNA-tr), or both transcripts (siRNA-tot). Total and specific mRNA levels were determined by using specific TaqMan assays in comparison to non-targeting siRNA (siRNA-ctr; set to 1 and shown in white bars). Results represent means of three $\mathrm{PHH}$ donors with two individual replicates. B. qRT-PCR analysis of the selected proliferative genes following overexpression of each PPARa isoform and treatment with the solvent control, DMSO, of mouse AML12 (top) and human hepatoma HuH7 cells (bottom). C. Quantitative qRT-PCR analysis of the selected pro-inflammatory genes following overexpression of each PPARa isoform and treatment with the solvent control, PBS, of mouse AML12 (top) and human hepatoma HuH7 cells (bottom).

Additional file 3: Figure S1. Analysis of endogenous expression of PPARa-wt and PPARa-tr in mouse and human cell lines. A. Quantitative real-time RT-PCR analysis of PPARA-wt (black bars) and PPARa-tA (grey bars) mRNA levels in selected liver homogenate $(\mathrm{LH})$, primary human hepatocytes (PHH), mouse AML12 (AML12) and human Huh7 cells. The data are represented relative to the liver homogenate $(\mathrm{LH})$ (set as 1). B. Representative Western blot analysis of PPARa-wt and PPARa-tr protein expression in the liver homogenate $(\mathrm{LH}), \mathrm{AML} 12$ and PHH cells. C. Despite of PPARA-tr mRNA expression, we could not detect PPARa-tr protein expression in $\mathrm{HuH7}$ cells (the most right lane at the western blot). To exclude technical problems, western blot analysis was performed following transfection of HuH7 cells with PPARa-tr expression plasmid (left lane on the blot) and $24 \mathrm{~h}$ later with indicated siRNAs. Densitometric evaluation of the bands is shown on the bottom and given relative to the PPARa-tr overexpression conditions.

Additional file 4: Figure S3. Cell viability analysis following PPARa-tr overexpression in human ovarian cancer SKOV3 cells. SKOV3 cells were transfected with indicated constructs treated with $100 \mu \mathrm{M}$ clofibrate (A) or $10 \mu \mathrm{M}$ GW7647 (B) and cell viability was measured using CellTiterGlo ${ }^{\oplus}$ assay at the indicated days. The viability curves are shown relative to the pcDNA3-transfected cells treated with solvent control, DMSO, set as $100 \%$ (dashed line). Error bars indicate standard deviation between three independent experiments measured in triplicates. * indicates significance $p<0.05$.

\section{Abbreviations}

ACOX1: Acyl-CoA oxidase 1; APOC3: Apolipoprotein C-III; CCL2: Chemokine (C-C motif) ligand 2; CDK1: Cyclin-dependent kinase 1; CDK4: Cyclin-dependent kinase 1; DMSO: Dimethylsulfoxide; HMGCS2: 3-hydroxy-3-methylglutaryl-COA synthase 2; IL1B: Interleukin 1 beta; MYC: V-Myc Avian Myelocytomatosis Viral Oncogene Homolog; PCNA: Proliferating cell nuclear antigen; PDK4: Pyruvate dehydrogenase kinase, isozyme 4; PHH: Primary human hepatocytes;

PPARa: Peroxisome proliferator activated receptor alpha; PTGS2: Prostaglandinendoperoxide synthase 2; siRNA: small interfering RNA; TNFa: Tumor necrosis factor alpha; WY14,643: 4-chloro-6-(2,3-xylidino)-2-pyrimidinylthio acetic acid.

\section{Competing interests}

The authors declare that they have no competing interests.

\section{Authors' contributions}

MT, CB and KK designed and carried out the experiments and TSW contributed primary human hepatocytes. SM provided statistical analyses. MT and UMZ wrote the manuscript. MS provided support in the final revision of the manuscript. UMZ and TSW obtained funding for the study. All authors read and approved the final manuscript.

\section{Acknowledgements}

We are very grateful to Igor Liebermann, Britta Klumpp and Kyoko Momoi for expert technical assistance. The authors are indebted to the Charitable Foundation Human Tissue and Cell Research, Regensburg, for making human tissue available for research. We thank Toshiya Tanaka for providing us human CDNA of PPARa. Furthermore, the authors thank Steven Dooley for providing mouse AML12 cell line. We thank Heiko van der Kuip, Werner Schroth and Oliver Burk for the critical and fruitful discussions. This study was supported by the German Federal Ministry of Education and Research (Virtual Liver Network Grants 0315755 to UMZ and 0315753 to TSW) and by the Robert Bosch Foundation, Stuttgart, Germany.

\section{Author details}

'Dr. Margarete Fischer-Bosch Institute of Clinical Pharmacology, Auerbachstr. 112, 70736, Stuttgart, and University of Tuebingen, Tuebingen, Germany. ${ }^{2}$ University Children Hospital (KUNO), Regensburg University Hospital, Regensburg, Germany. ${ }^{3}$ Department of Clinical Pharmacology, University of Tuebingen, Tuebingen, Germany. ${ }^{4}$ Present address: MUON-STAT, Klugestraße 28, 70197 Stuttgart, Germany. 
Received: 22 January 2015 Accepted: 19 June 2015

\section{Published online: 30 June 2015}

\section{References}

1. Ashby J, Brady A, Elcombe CR, Elliott BM, Ishmael J, Odum J, et al. Mechanistically-based human hazard assessment of peroxisome proliferatorinduced hepatocarcinogenesis. Hum Exp Toxicol. 1994;13 Suppl 2:S1-117.

2. Beaumont J, Arias T, Ravassa S, Diez J. Overexpression of human truncated peroxisome proliferator-activated receptor induces apoptosis in $\mathrm{HL}-1$ cardiomyocytes. Cardiovasc Res. 2008;79:458-63.

3. Bramow S, Ott P, Thomsen Nielsen F, Bangert K, Tygstrup N, Dalhoff K. Cholestasis and regulation of genes related to drug metabolism and biliary transport in rat liver following treatment with cyclosporine A and sirolimus (Rapamycin). Pharmacol Toxicol. 2001;89:133-9.

4. Contreras AV, Torres N, Tovar AR. PPAR- as a Key Nutritional and Environmental Sensor for Metabolic Adaptation. Adv Nutr Int Rev J. 2013;4:439-52.

5. Damm G, Pfeiffer E, Burkhardt B, Vermehren J, Nüssler AK, Weiss TS. Human parenchymal and non-parenchymal liver cell isolation, culture and characterization. Hepatol Int. 2013;7:951-8.

6. Diradourian C, Girard J, Pégorier J-P. Phosphorylation of PPARs: from molecular characterization to physiological relevance. Biochimie. 2005;87:33-8 [New Developments in Metabolic Syndrome].

7. El Kebbaj Z, Andreoletti P, Mountassif D, Kabine M, Schohn H, Dauça M, et al. Differential Regulation of Peroxisome Proliferator-Activated Receptor (PPAR)-a1 and Truncated PPARa2 as an Adaptive Response to Fasting in the Control of Hepatic Peroxisomal Fatty Acid $\beta$-Oxidation in the Hibernating Mammal. Endocrinology. 2009;150:1192-201.

8. Feldman PL, Lambert MH, Henke BR. PPAR modulators and PPAR pan agonists for metabolic diseases: the next generation of drugs targeting peroxisome proliferator-activated receptors? Curr Top Med Chem. 2008:8:728-49.

9. Gervois P, Torra IP, Chinetti G, Grötzinger T, Dubois G, Fruchart JC, et al. A truncated human peroxisome proliferator-activated receptor alpha splice variant with dominant negative activity. Mol Endocrinol. 1999;13:1535-49.

10. Gervois P, Vu-Dac N, Kleemann R, Kockx M, Dubois G, Laine B, et al. Negative Regulation of Human Fibrinogen Gene Expression by Peroxisome Proliferator-activated Receptor a Agonists via Inhibition of CCAAT Box/Enhancerbinding Protein $\beta$. J Biol Chem. 2001;276:33471-7.

11. Goikoetxea MJ, Beaumont J, González A, López B, Querejeta R, Larman M, et al. Altered cardiac expression of peroxisome proliferator-activated receptor-isoforms in patients with hypertensive heart disease. Cardiovasc Res. 2006;69:899-907.

12. Gonzalez FJ, Shah YM. PPARalpha: mechanism of species differences and hepatocarcinogenesis of peroxisome proliferators. Toxicology. 2008;246:2-8.

13. Grygiel-Górniak B. Peroxisome proliferator-activated receptors and their ligands: nutritional and clinical implications-a review. Nutr J. 2014;13:17.

14. Hanselman JC, Vartanian MA, Koester BP, Gray SA, Essenburg AD, Rea TJ, et al. Expression of the mRNA encoding truncated PPAR alpha does not correlate with hepatic insensitivity to peroxisome proliferators. Mol Cell Biochem. 2001;217:91-7.

15. Kino T, Su YA, Chrousos GP. Human glucocorticoid receptor isoform $\beta$ : recent understanding of its potential implications in physiology and pathophysiology. Cell Mol Life Sci. 2009;66:3435-48.

16. Klein K, Thomas M, Winter S, Nussler AK, Niemi M, Schwab M, et al. PPARA: a novel genetic determinant of CYP3A4 in vitro and in vivo. Clin Pharmacol Ther. 2012;91:1044-52.

17. Klein $\mathrm{K}$, Winter S, Turpeinen M, Schwab M, Zanger UM. Pathway-Targeted Pharmacogenomics of CYP1A2 in Human Liver. Front Pharmacol. 2010;1:129.

18. Koslowski MJ, Kübler I, Chamaillard M, Schaeffeler E, Reinisch W, Wang G, et al. Genetic variants of Wnt transcription factor TCF-4 (TCF7L2) putative promoter region are associated with small intestinal Crohn's disease. PloS One. 2009;4, e4496.

19. Maggiora M, Bologna $M$, Cerù MP, Possati L, Angelucci $A$, Cimini $A$, et al. An overview of the effect of linoleic and conjugated-linoleic acids on the growth of several human tumor cell lines. Int J Cancer. 2004;112:909-19.

20. Mandard S, Patsouris D. Nuclear Control of the Inflammatory Response in Mammals by Peroxisome Proliferator-Activated Receptors. PPAR Res. 2013;2013, e613864.

21. Misra P, Reddy JK. Peroxisome proliferator-activated receptor-a activation and excess energy burning in hepatocarcinogenesis. Biochimie. 2014;98:63-74
22. Morimura K, Cheung C, Ward JM, Reddy JK, Gonzalez FJ. Differential susceptibility of mice humanized for peroxisome proliferator-activated receptor to Wy-14,643-induced liver tumorigenesis. Carcinogenesis. 2006;27:1074-80.

23. Mukherjee R, Jow L, Noonan D, McDonnell DP. Human and rat peroxisome proliferator activated receptors (PPARs) demonstrate similar tissue distribution but different responsiveness to PPAR activators. J Steroid Biochem Mol Biol. 1994;51:157-66.

24. Palmer CNA, Hsu M-H, Griffin KJ, Raucy JL, Johnson EF. Peroxisome Proliferator Activated Receptor-a Expression in Human Liver. Mol Pharmacol. 1998;53:14-22.

25. Peters JM, Cheung C, Gonzalez FJ. Peroxisome proliferator-activated receptor-a and liver cancer: where do we stand? J Mol Med. 2005;83:774-85.

26. Peters JM, Shah YM, Gonzalez FJ. The role of peroxisome proliferatoractivated receptors in carcinogenesis and chemoprevention. Nat Rev Cancer. 2012;12:181-95.

27. Pineda Torra I, Jamshidi Y, Flavell DM, Fruchart J-C, Staels B. Characterization of the Human PPARa Promoter: Identification of a Functional Nuclear Receptor Response Element. Mol Endocrinol. 2002;16:1013-28.

28. Pozzi A, Ibanez MR, Gatica AE, Yang S, Wei S, Mei S, et al. Peroxisomal Proliferator-activated Receptor-a-dependent Inhibition of Endothelial Cell Proliferation and Tumorigenesis. J Biol Chem. 2007;282:17685-95.

29. Pyper SR, Viswakarma N, Yu S, Reddy JK. PPARalpha: energy combustion, hypolipidemia, inflammation and cancer. Nucl Recept Signal. 2010;8, e002.

30. Qu A, Jiang C, Cai Y, Kim J-H, Tanaka N, Ward JM, et al. Role of Myc in hepatocellular proliferation and hepatocarcinogenesis. J Hepatol. 2014;60:331-8.

31. Saidi SA, Holland CM, Charnock-Jones DS, Smith SK. In vitro and in vivo effects of the PPAR-alpha agonists fenofibrate and retinoic acid in endometrial cancer. Mol Cancer. 2006:5:13.

32. Schroder A, Klein K, Winter S, Schwab M, Bonin M, Zell A, et al. Genomics of ADME gene expression: mapping expression quantitative trait loci relevant for absorption, distribution, metabolism and excretion of drugs in human liver. Pharmacogenomics J. 2013;13:12-20.

33. Skrypnyk N, Chen X, Hu W, Su Y, Mont S, Yang S, et al. PPARa Activation Can Help Prevent and Treat Non-Small Cell Lung Cancer. Cancer Res. 2014;74:621-31.

34. Spurgeon SL, Jones RC, Ramakrishnan R. High throughput gene expression measurement with real time PCR in a microfluidic dynamic array. PloS One. 2008; 3 , e1662.

35. Tanaka T, Takeno T, Watanabe $\mathrm{Y}$, Uchiyama $\mathrm{Y}$, Murakami T, Yamashita $\mathrm{H}$, et al. The generation of monoclonal antibodies against human peroxisome proliferator-activated receptors (PPARs). J Atheroscler Thromb. 2002:9:233-42.

36. Tateno C, Yamamoto T, Utoh R, Yamasaki C, Ishida Y, Myoken Y, et al. Chimeric Mice with Hepatocyte-humanized Liver as an Appropriate Model to Study Human Peroxisome Proliferator-activated Receptor-a. Toxicol Pathol. 2015;43(2):233-48

37. Thomas M, Bayha C, Vetter S, Hofmann U, Schwarz M, Zanger UM, et al. Activating and Inhibitory Functions of WNT/ $\beta$-catenin in the Induction of Cytochromes P450 by Nuclear Receptors in HepaRG Cells. Mol Pharmacol. 2015;87:1013-20.

38. Thomas M, Burk O, Klumpp B, Kandel BA, Damm G, Weiss TS, et al. Direct transcriptional regulation of human hepatic cytochrome P450 3A4 (CYP3A4) by peroxisome proliferator-activated receptor alpha (PPARa). Mol Pharmacol. 2013:83:709-18.

39. Thomas M, Rieger JK, Kandel BA, Klein K, Zanger UM. Targeting Nuclear Receptors with Lentivirus-Delivered Small RNAs in Primary Human Hepatocytes. Cell Physiol Biochem. 2014;33:2003-13.

40. Van Bilsen M, van Nieuwenhoven FA. PPARs as therapeutic targets in cardiovascular disease. Expert Opin Ther Targets. 2010;14:1029-45.

41. Wadosky KM, Willis MS. The story so far: post-translational regulation of peroxisome proliferator-activated receptors by ubiquitination and SUMOylation. Am J Physiol. 2012;302:H515-26.

42. Wahli W, Michalik L. PPARs at the crossroads of lipid signaling and inflammation. Trends Endocrinol Metab. 2012;23:351-63.

43. Wright MB, Bortolini M, Tadayyon M, Bopst M. Minireview: Challenges and opportunities in development of PPAR agonists. Mol Endocrinol. 2014:28(11):1756-68.

44. Yang Q, Nagano T, Shah Y, Cheung C, Ito S, Gonzalez FJ. The PPAR?Humanized Mouse: A Model to Investigate Species Differences in Liver Toxicity Mediated by PPAR? Toxicol Sci. 2008;101:132-9. 
45. Yokoyama $Y$, Xin B, Shigeto T, Umemoto M, Kasai-Sakamoto A, Futagami M, et al. Clofibric acid, a peroxisome proliferator-activated receptor alpha ligand, inhibits growth of human ovarian cancer. Mol Cancer Ther. 2007;6:1379-86

46. Youssef J, Badr M. Peroxisome proliferator-activated receptors and cancer: challenges and opportunities. Br J Pharmacol. 2011;164:68-82.

Submit your next manuscript to BioMed Central and take full advantage of:

- Convenient online submission

- Thorough peer review

- No space constraints or color figure charges

- Immediate publication on acceptance

- Inclusion in PubMed, CAS, Scopus and Google Scholar

- Research which is freely available for redistribution 